\title{
Tradições discursivas no gênero editorial praticado no Brasil e na Argentina: a expressão do campo dêitico nos séculos XX e XXI
}

\author{
Lucineudo Machado IRINEU (D) \\ Universidade Estadual do Ceará (UECE)
}

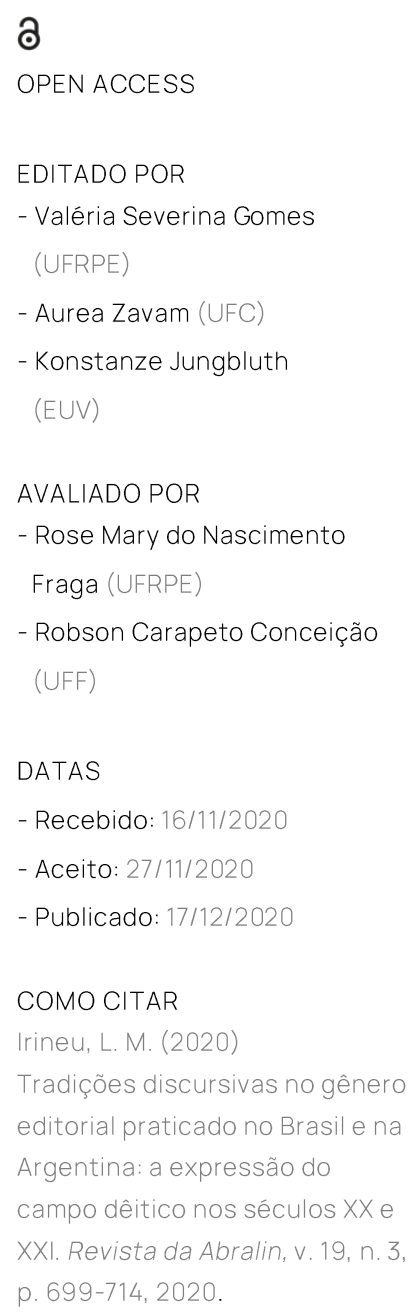

\section{RESUMO}

Este artigo objetiva analisar os recursos dêiticos que evidenciam a expressão diacrônica do conjunto de imagens de si projetadas por editorialistas do Jornal do Brasil (JB) e do Clarín (CL) em textos publicados nos séculos XX e XXI, mais precisamente entre os anos de 1945 e 2014. Para dar conta desse objetivo, do ponto de vista teórico, debruçamo-nos sobre o conceito de tradições discursivas a partir dos trabalhos de Kabatek (2001) e outros pesquisadores, ampliando-o na direção de um diálogo com os estudos em Análise do Discurso. Do ponto de vista metodológico, voltamo-nos ao exame de recursos dêiticos pessoais, temporais, sociais e modais e sua realização como elementos linguístico-discursivos indiciadores da emergência das imagens de si nos 50 textos que compõem o corpus, segundo cada periódico selecionados, em termos de mudanças e permanências no recorte temporal estabelecido. Do ponto de vista analítico, constatamos, de modo amplo: (i) nos dados relativos à primeira geração de textos (1945 a 1979) do JB, predomínio de dêiticos na primeira pessoa, ou seja, no plural inclusivo (expressão do ponto de vista enunciativo), seguido de vestígios de mudança nesta categoria na segunda geração de textos (1980 a 2014); e (ii) nos dados relativos à primeira geração de textos (1945 a 1979) do CL, predomínio de dêiticos temporais de natureza adverbial (expressão de tempo presente que se reporta a um passado próximo e/ou a um passado distante), seguido de vestígios de vestígios de mudança nesta categoria na segunda geração de textos (1980 a 2014). 


\section{REVISTA DA ABRALIN}

\section{ABSTRACT}

This article aims to analyze the deictic resources that show the diachronic expression of the set of images of themselves projected by editorialists from Jornal do Brasil (JB) and Clarín (CL) in texts published in the 20th and 21st centuries, more precisely between the years 1945 and 2014. To achieve this objective, from a theoretical point of view, we focus on the concept of discursive traditions based on the work of Kabatek (2001) and other researchers, expanding it towards a dialogue with studies in Discourse Analysis. From a methodological point of view, we turn to the examination of personal, temporal, social and modal resources and their realization as linguistic-discursive elements that indicate the emergence of images of the self in the 50 texts that make up the corpus, according to each selected journal, in terms of changes and permanences in the established time frame. From an analytical point of view, we found, broadly: (i) in the data relating to the first generation of texts (1945 to 1979) by JB, predominance of deictics in the first person, that is, in the inclusive plural (expression of the point of view enunciative), followed by traces of change in this category in the second generation of texts (1980 to 2014); and (ii) in the data related to the first generation of texts (1945 to 1979) of the CL, predominance of temporal deictics of an adverbial nature (expression of present time that refers to a near past and / or a distant past), followed by traces of traces of change in this category in the second generation of texts (1980 to 2014).

\section{PALAVRAS-CHAVE}

Tradições discursivas. Editoriais. Campo dêitico. Séculos XX e XXI.

\section{KEYWORDS}

Discursive traditions. Editorials. Deictic field. $20^{\text {th }}$ and $21^{\text {st }}$ centuries.

\section{Introdução}

Tomando como pressuposto que "não se deve esquecer que tradições discursivas estão relacionadas ao linguístico, mas não são, de modo algum, puramente linguísticas" (KOCH, 1997, p. 79) e que áreas como a Análise do Discurso "não rejeitam, na atualidade, a perspectiva histórica para oferecer uma confirmação genética a suas respectivas hipóteses" (KABATEK, 2001a, p. 07), neste artigo, parto dos estudos discursivos e filológicos para analisar os recursos dêiticos que evidenciam a expressão diacrônica do conjunto de imagens de si projetadas por editorialistas do Jornal do Brasil (JB) e do 


\section{REVISTA DA ABRALIN}

Clarín (CL) em textos publicados nos séculos XX e XXI. A execução desse objetivo orienta-se pela tese que postulo de o conceito de tradições discursivas (doravante TD) lança luz à investigação de fenômenos discursivos, a exemplo da expressa diacrônica de imagens de si.

Em uma pesquisa qualitativa, analiso 50 exemplares de editoriais organizados em duas grandes gerações de 35 anos cada (de 1945 a 1979 e de 1980 a 2014) e coletados/editados, entre 2013 e 2014 , quando estive na Universidade de Buenos Aires (doravante UBA) como pesquisador-bolsista em estágio doutoral realizado com financiamento do Programa de Doutorado Sanduíche no Exterior (PDSE/CAPES), experiência essa que me possibilitou o acesso aos arquivos públicos do Clarín preservados na Biblioteca Nacional Argentina, bem como o acesso às técnicas de manuseio e tratamento de material histórico para a realização de pesquisas científicas nos acervos do CL e do JB.

Por sua natureza interdisciplinar, a pesquisa empreendida se mostra como uma possibilidade de ampliação dos estudos sobre tradições discursivas na medida em que se volta para a análise de questões textuais, genéricas e, sobretudo, discursivas, como vemos a seguir. Assim, de início, situo o conceito de tradições discursivas do qual parto para a análise que empreendo nos dados selecionados.

\section{Tradições discursivas do campo dêitico em editoriais do JB e do CL: notações conceituais}

Johannes Kabatek dedicou-se ao estudo de tradições discursivas, redimensionando-o a partir da análise dos vestígios de mudança e de permanência pelos quais passam os índices linguístico-textuais ao longo de dado período histórico.

Segundo Kabatek (2001a), as pesquisas em Análise do Discurso não devem descartar a perspectiva diacrônica para oferecer uma confirmação histórica a suas questões de pesquisa (e para oferecer uma interpretação histórica a seus objetos de pesquisa) com relação aos mecanismos e princípios que regem a comunicação verbal. Ao tomar as TD como modos de comunicação analisáveis "em categorias da pragmática universal e que servem para identificar os traços universais próprios de cada constelação discursiva no plano histórico" (KABATEK, 2001a, p. 08, tradução nossa ${ }^{1}$ ), o teórico argumenta que as tradições discursivas são espécies de moldes históricos e normativos que se repetem com valor de signo, ou seja, que se apresentam segundo formas textuais, textos ou modos de dizer no curso histórico, no plano da significação.

Ao investigar as tradições discursivas medievais em textos jurídicos castelhanos, Kabatek (2001b) estabelece uma relação entre transformação linguística e tradição que passa a ser observada

\footnotetext{
${ }^{1}$ No original: "modos de comunicación, que se miden en categorías de pragmática universal y que sirven para identificar los rasgos universales propios de cada constelación discursiva en el plan histórico".
} 


\title{
REVISTA DA ABRALIN
}

nos estudos linguísticos de modo mais evidente no que se refere à busca da autenticidade da variação diacrônica, priorizando-se a análise comparada de textos de mesma natureza ao longo do tempo.

Neste sentido, a maior contribuição dada pelo autor à Teoria das Tradições Discursivas foi o fato de haver postulado que, além de estarem situadas em um nível histórico da linguagem distinto do nível em que estão situadas as línguas, as TD apresentam traços definidores ligados à significação, ou seja, apresentam valor de signo próprio, enfatizando que: (i) nem toda tradição é discursiva (as pinturas, por exemplo, são tradições, mas não do discurso) e que (ii) nem toda repetição linguística é uma TD.

Este pensamento de Kabatek (2001b) destaca que a repetição de uma forma textual, de um texto e/ou de um modo de dizer só pode ser tomada como uma TD a partir do momento em que se estabelece no curso histórico de modo recorrente e com valor de signo (ou seja, com sua expressão para além do plano do significante), o que significa dizer que as combinações linguísticas que realizamos diariamente na construção de frases/períodos não necessariamente são TD.

Partindo do reconhecimento de que as TD estão circunscritas, de início, ao nível histórico proposto por Coseriu (1980), Kabatek (2001, p. 99, tradução nossa ${ }^{2}$ ) confirma que a historicidade das tradições discursivas de fato é distinta da historicidade das línguas na medida em que:

\begin{abstract}
A historicidade das línguas corresponderia às línguas históricas como o francês, o alemão e o espanhol com suas variedades diatópicas, diastráticas e diafásicas; ao passo em que a historicidade discursiva seria, por exemplo, a da história dos gêneros textuais, dos atos de fala, dos gêneros literários e retóricos e dos estilos. Falar seria, pois, uma atividade universal que se realizaria através de um duplo filtro tradicional: a intenção do ato comunicativo teria que passar em cada momento pela ordem linguística que encadeia os signos de uma língua segundo suas regras sintáticas e pela ordem textual que atualiza certas tradições discursivas.
\end{abstract}

Das palavras de Kabatek (2001), depreende-se que as imagens de si de editorialistas, quando estudadas sob a prisma da diacronia, estão relacionadas à "historicidade discursiva", ou seja, à historicidade "dos gêneros", "dos estilos", dos modos de dizer.

Em termos composicionais, uma TD pode se configurar com base em qualquer elemento significável, seja de forma ou de conteúdo. Este elemento está envolvido em um processo de evocação que estabelece um laço de união entre atualização e tradição de dado elemento no discurso. Trata se de uma relação que se estabelece semioticamente, entre pelo menos dois enunciados "seja enquanto ato de enunciação em si, seja enquanto elementos referenciais", em função da forma textual ou dos elementos linguístico-discursivos empregados (KABATEK, 2006, p. 09).

Destaque-se que a relação entre as tradições se dá em função de um conteúdo, de uma língua e/ou de uma forma com base em duas situações (ou mais) que evocam textos relacionáveis. A estas situações dá-se o nome de constelação de entornos (KABATEK, 2006), o que, a nosso ver,

\footnotetext{
${ }^{2}$ No original: "la historicidad de las lenguas correspondería a las lenguas históricas como francés, alemán o español con sus variedades diatópicas, diastráticas y diafásicas; mientras que la historicidad discursiva sería, por ejemplo, la de la historia de los géneros textuales, los actos de habla, los géneros literarios y retóricos y los estilos. Hablar sería, pues, una actividad universal que se realizaría a través de un doble filtro tradicional: la intención del acto comunicativo tendría que pasar en cada momento por el orden lingüístico que encadena los signos de una lengua según sus reglas sintácticas y por el orden textual que actualiza ciertas tradiciones discursivas".
} 


\section{REVISTA DA ABRALIN}

corresponde ao conjunto de fatores contextuais e/ou circunstanciais (tempo, espaço, dentre outros) em relação aos quais se concretizam os atos de linguagem executados pelos indivíduos.

Neste tocante, na concepção de Kabatek (2006), no plano da enunciação, sempre há uma ação historicamente determinada em duas direções: produz-se um texto segundo a tradição histórica de uma língua (uma gramática e um léxico) e segundo uma TD. Por este pressuposto confirma-se a hipótese de que a historicidade de uma tradição no discurso reside de fato na repetição de algo (uma forma textual, um texto ou um modo de dizer), com valor significável, em termos de continuidade ou de ruptura. Assim, Kabatek (2007, p. 07) conceitua TD como:

\footnotetext{
A repetição de um texto ou de uma forma textual ou de uma maneira particular de escrever ou falar que adquire valor de signo próprio (portanto é significável). Pode-se formar em relação a qualquer finalidade de expressão ou qualquer elemento de conteúdo, cuja repetição estabelece uma relação de união entre atualização e tradição; qualquer relação que se pode estabelecer semioticamente entre dois elementos de tradição (atos de enunciação ou elementos referenciais) que evocam uma determinada forma textual ou determinados elementos linguísticos empregados (grifos meus).
}

O conceito proposto por Kabatek (2007) me parece crucial para a compreensão da face diacrônica das imagens de si e de suas evidências linguístico-discursivas, na medida em que trata das TD como uma repetição, no plano da significação, em três dimensões basilares: o texto, a forma textual e a maneira particular de escrever ou falar. Por "forma textual", compreendem-se as estruturas textuais recorrentes que se constituem como TD no curso de dado recorte temporal (uma forma verbal, por exemplo); por "texto", compreendem-se segmentos textuais (porções de textos) mais complexas que estruturas (a exemplo da abertura de uma carta) consideradas TD; por "maneira particular de escrever ou falar" (dimensão que me interessa particularmente), compreendem-se os modos de dizer, a exemplo das formas de interação em dados gêneros.

Para Kabatek (2007), assim como as formas textuais, os textos e os modos de dizer, os gêneros são também tradicionais e podem ser conceituados como TD. Esta afirmação, feita à luz dos postulados de Maingueneau (2008), pode ser assim compreendida: a construção das imagens de si (ethos) e de fenômenos discursivos em diacronia relacionados ao estilo está, de certo modo, condicionada à inscrição destes fenômenos em uma cena genérica.

O valor de "signo próprio" a que se refere o autor está relacionado ao fato de uma repetição só poder ser tomada como TD quando significa, ou seja, quando constrói significado para além do significante, para além da forma linguística. Se, então, uma TD é uma repetição "com valor de signo próprio", é no curso do tempo que o elemento repetido estabelece uma relação de união entre "atualização e tradição" no plano da mudança ou da inovação.

Ao conceber ethos como a imagem de si que o enunciador faz revelar no ato enunciativo através da instauração de uma voz social, ou seja, como um fenômeno discursivo que deixa marcas de sua existência na cadeia enunciativa, toma-se a noção de TD proposta por Kabatek (2007) como um requisito conceitual que estabelece um diálogo epistemológico com a Análise do Discurso.

O conceito proposto por Kabatek (2007) iluminou e segue iluminando desdobramentos dos estudos sobre TD. É graças aos trabalhos dos representantes da Filologia Românica alemã que os 


\section{REVISTA DA ABRALIN}

estudos sobre o fenômeno tradicional no discurso expandiram-se de modo surpreendente para outros domínios da Linguística nos últimos tempos, a exemplo de sua inserção na Análise de Gêneros.

Assim como a postura epistemológica que assumo nesta pesquisa, outros pesquisadores assumiram para si a tarefa de relacionar seus trabalhos sobre TD às "diferentes heranças das distintas escolas", como é o caso de Zavam (2009), na tese de doutorado em que delineia uma metodologia para a análise de gêneros do âmbito jornalístico, considerando os processos de modificação pelos quais passa um gênero, no que se refere aos traços de mudança e de permanência que apresentam em suas dimensões textual e contextual.

Acredito que a repetição destes modos de dizer, na constituição do ethos, revela certos índices linguístico-discursivos que sinalizam para tradições discursivas que, em conjunto, ao longo dos séculos XX e XXI, expressam o modo cultural e social de ser dos povos latinos cuja identidade se constrói em perspectiva híbrida (mesclas culturais) e intercultural (contato entre culturas heterogêneas), em constante mudança, entre a tradição e a atualização.

Todo este processo se dá no plano da significação: os índices que sinalizam para as TD se repetem com valor de signo ao longo dos séculos; as imagens de si que os enunciadores deixam revelar no discurso jornalístico se constroem com valor de signo de uma geração a outra de textos. Em síntese, a expressão das imagens de si nos editoriais do JB e do CL se dá essencialmente no plano da significação, na integração entre forma e sentido.

Percorrendo o campo da significação, analisamos os 50 editoriais que compõem nosso corpus. O percurso operacional traçado como rota norteadora para a compilação e para a análise dos dados, assim como todo o marco teórico desta pesquisa, foi constituído em perspectiva interdisciplinar, a fim de oferecer condições para que nosso objeto de análise fosse analisado em sua face discursiva, como vemos a seguir.

\section{Tradições discursivas no gênero editorial praticado no Brasil e na Argentina: a expressão do campo dêitico nos séculos XX e XXI}

Os elementos dêiticos estão no plano da enunciação para revelar "as coordenadas do falante no âmbito dos espaços físicos textuais" (CAVALCANTE, 2000, p. 03). Sobre estes elementos, Maingueneau (2008) destaca que as imagens de si se expressam nas cenografias em termos de cronografia, topografia e participantes, em função dos dêiticos expressos na cena de enunciação.

A análise das diversas imagens de si nos dois jornais revelou recorrências de elementos dêiticos que se repetem com valor de signo próprio, ou seja, para indicar o ponto de vista enunciativo (dêiticos pessoais), as coordenadas cronográficas e topográficas (dêiticos temporais e espaciais), bem 


\section{REVISTA DA ABRALIN}

como as circunstâncias, os papéis sociais dos enunciadores e a referência metalinguística a porções do discurso (dêiticos modais, sociais e discursivo-textuais, respectivamente).

A seguir, analisamos textos do Jornal do Brasil (JB) e do Clarín (CL), nessa ordem.

\section{Os editoriais do Jornal do Brasil (JB)}

Nos textos do JB, observa-se a recorrência de dêiticos de primeira pessoa (pronomes e verbos, principalmente), marcando o plural inclusivo (BENVENISTE, 1995) nos exemplares cuja enunciação se dá segundo um ponto de vista enunciativo em que o "nós" representa um "eu + tu (vós)", na projeção de uma pessoa amplificada, de um eu dilatado. Esta forma tradicional de dizer configura-se como uma estratégia de captação dos coenunciadores, pelo enunciador, com o objetivo de que venham a aderir ao posicionamento crítico defendido pelo periódico nos editoriais.

Nos dados, verifica-se a ocorrência do dêitico "nós" como plural inclusivo em toda a primeira geração de textos do JB, mais especificamente em 11 (onze) dos 13 (treze) editoriais analisados. Exemplos desta ocorrência nas décadas de 40,50, 60 e 70 do século XX são expostos a seguir:

\footnotetext{
(JB 02/1946) Hoje transcorre a data mais | importante de NOSSA historia. | Em 7 de setembro de 1822, | uma nação americana entrou | para o concerto das nações li- | vres. O Brasil adquiriu sua po- | sição no mundo, iniciando a | marcha na estrada da civili- | zação.

(JB 06/1958) O ministro Macedo Soares se tem | mostrado incansável na execução dêste plano, que foi | sempre o objetivo da NOSSA política externa, quando | se trata de proteger a confiança que deve reinar sem-I pre entre povos, fadados dentro de algum tempo a | formar um conjunto de interêsses comuns.

(JB 09/1967) Guevara com seu temperamento militante | de revolucionário autêntico passou a afastar-se | cada vez mais das tendências aburguesantes do | médio comunismo soviético dos NOSSOS dias.

(JB 13/1979) Ainda sob os ecos da feliz conclusão dos | acordos de Itaipu, passo importante na pacificação | da fronteira Sul da diplomacia brasileira, a visita | do Presidente Figueiredo a Caracas - sua primei- | ra viagem ao exterior como Chefe de Estado - | aprofunda uma outra linha fundamental dos NOSSOS | contatos externos
}

Somente nos editoriais de 1949 e 1976, que debatem a posição assumida pelo Brasil no contexto da Segunda Guerra Mundial e o marasmo da política brasileira na década de 1970, há a ocorrência de terceira pessoa como ponto de vista enunciativo. Devemos destacar que, nesta geração, registra-se a ocorrência de "Este Jornal" (JB 04/1952) com valor dêitico, pelo qual o enunciador fala em nome dos que fazem o JB e revela um ponto de vista institucional marcado pelo uso desta expressão.

Do mesmo modo que com os dêiticos pessoais, registramos a ocorrência de dêiticos temporais, pelos quais se instaura a cronografia na cena enunciativa. Estes dêiticos circunscrevem a enunciação em um tempo presente (uma tendência no discurso jornalístico, mais especificamente nos editoriais), que se reporta a um passado próximo e/ou a um passado distante, tomando-os como elemento 


\section{REVISTA DA ABRALIN}

de reflexão sobre o passado histórico e cultural do povo portenho como uma tradição. A dêixis temporal traça as coordenadas da enunciação e a consequente instauração do enunciador no tempo discursivo. Dos 13 exemplares analisados, somente o de 1955 não apresenta dêiticos temporais de natureza adverbial, estando a cargo dos tempos verbais o estabelecimento das coordenadas temporais, como vemos nestes trechos:

\footnotetext{
(JB 01/1945) AGORA quando estamos no li- | miar de um novo ano, que todos | esperamos e desejamos seja o do | triunfo e da paz, não poderia ser | mais oportuna a palavra do Mi- | nistro do Exterior do Brasil, avi- | ventando na memoria dos povos | estrangeiros as linhas gerais e | definitivas da nossa política in-| ternacional.
}

(JB 04/1952) Mais uma etapa vence o Jornal do Brasil ao completar, | HOJE, 62 anos de existencia. Fazendo retrospecto de sua | caminhada, é-nos grato salientar que, tendo adotado, | desde a sua fundação, patriótica orientação, ATÉ HOJE tem | demonstrado absoluta fidelidade os princípios que inspira- | ram sua ação orientadora da opinião pública.

(JB 08/1964) Muito se fala e muito se procura fazer HOJE | EM DIA no Brasil acêrca da "imagem nacional", | isto é, da imagem que o Brasil projeta de si mesmo no exterior.

(JB 11/1973) A notícia das agências fala de um comboio | ferroviário que saiu NA SEXTA-FEIRA PASSADA de | Antofagasta, no Chile, com um carregamento de | 60 toneladas de cobre da mina de Mantos Blan- | cos, com destino a São Paulo.

Por sua vez, os dêiticos espaciais cumprem, nos editoriais analisados, a função de situar a enunciação em termos de topografia, em coordenadas espaciais do geral para o particular (do contexto latino-americano para o contexto brasileiro), ou o contrário, como em alguns casos. A tradição se instaura na retratação de temas no contexto Brasil-América Latina. Dos 13 editoriais analisados, 11 apresentam dêiticos espaciais de natureza adverbial (somente nos exemplares de 1949 e 1952 não há registro destes elementos dêiticos, depreendendo-se as coordenadas topográficas por informação do cotexto e do contexto). Destaque para esses fragmentos:

(JB 05/1955) Disse o Ministro do Interior da Argentina que existe | liberdade de impressa NO SEU PAÍS. O que tem havido |é má interpretação, NO EXTERIOR, em certas providencias | contra jornais, como "La Prensa".

(JB 07/1961) Destacamos, de propósito, antes de | mais, que o Senhor Lincoln Gordon falou, | ontem, aos norte-americanos $\underline{\mathbf{A Q U I}}$ radica- | dos.

(JB 10/1970) Por isso mesmo não é de estranhar que, | encerrando ontem, EM BRASÍLIA, o Encontro Na| cional de Defesa do Patrimônio tenha aprovado | mais de 20 propostas para a defesa, preserva- | ção e

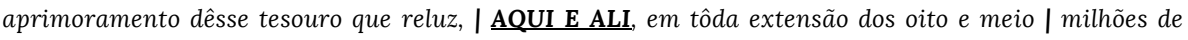
quilômetros quadrados do Brasil.

Registra-se também a ocorrência de outros dêiticos nos editoriais analisados da primeira geração de textos do JB. Observam-se: (i) presença de dêiticos sociais nos anos de 1945, 1961 e 1964; (ii) raros casos de dêiticos modais (presença do modal "assim" somente nos exemplares de 1945 e 1970); (iii) total ausência de dêiticos discursivo-textuais nos 13 exemplares. Destaca-se a ocorrência de 


\title{
REVISTA DA ABRALIN
}

certo modo significativa dos dêiticos sociais, pelos quais os enunciadores representam a si e aos coenunciadores com quem interagem em termos de papéis sociais assumidos e pretendidos (FONSECA, 1996). Os dêiticos sociais exprimem respeito do enunciador pelo coenunciador, representado como autoridade, como vemos nestes exemplos:

\begin{abstract}
(JB 01/1945) Isso acaba de dar incisiva | resposta a entrevista do Minis- | tro do Exterior, $\underline{\text { SENHOR Leão }}$ Veloso, | que, depois de passar em rápida | revista as características per- | manentes da nossa orientação | internacional, responde assim á | pergunta do jornalista sobre o | lugar previsto para o Brasil na | Conferencia da Paz.
\end{abstract}

(JB 07/1961) Ontem, perante seus concidadãos que | trabalham no Brasil, o Embaixador norte- | americano, SENHOR Lincoln Gordon, fêz um | discurso que pode representar, na área bra- | sileira, um ponto de partida tão simbólico | quanto o discurso de posse do Presidente | Kennedy na área norte-americana e inte- | rnacional.

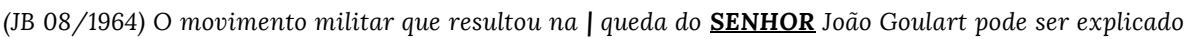
nas | suas intenções mas só será aceito na medida das | suas realizações.

Na sequência, é possível observar vestígios de mudança no modo como os editoriais do JB constroem o ponto de vista enunciativo nos exemplares da segunda geração de textos, notadamente a partir do século XXI. Em síntese, no século XX, na primeira geração, há predominância do plural inclusivo; já na segunda geração, há um princípio de mudança, já que, nos textos de 1982, 1988 e 1991 (03, ao total), a enunciação se dá em terceira pessoa, enquanto que, nos textos de 1985, 1994, 1997 e 2000 (04, ao total), há ocorrência de dêiticos de primeira pessoa, evidenciando o plural inclusivo (BENVENISTE, 1995). Nos exemplares do século XXI, mais especificamente nos anos de 2003, 2006, 2009, 2013 e 2014, a enunciação se concretiza também em terceira pessoa, como evidenciado nos trechos a seguir:

(JB 21/2003) Ao se aproximar dos últi- | mos dias, O ANO DE 2003 | ressaltou alguns traços | como garantia para ser | lembrado a título de referência | futura. Antes de tudo, pela apro- | vação das reformas tributárias e | da previdência, mediante | emendas constitucionais que | não conseguiram reunir apoio su- | ficiente para vencer a inércia | histórica.

(JB 22/2006) A CADA DIA vai se |_ampliando a já extensa | galeria de exemplos que fa- | zem da política brasileira um | mundo do faz-de-conta. A úl-| tima fantasia acrescentada à | expressão utilizada pelo mi| nistro Marco Aurélio Mello, ao | assumir a presidência do Tri- | bunal Superior Eleitoral | (TSE), é a relação de cerca de | 2.900 nomes de políticos im-I pedidos de disputar as elei- | ções.

(JB 23/2009) O resultado do Exame Nacional do Ensino / Médio (ENEM), disponível DESDE ONTEM na página do Ministério | da Educação na internet, evidencia o grau de degradação a que | chegou a educação pública no país.

(JB 24/2012) DIA 15 DE NOVEMBRO - data da Proclamação da República - | coincidiu com a data em que o Supremo Tribunal Federal | expediu as ordens para execução das prisões dos | condenados no caso do mensalão. 


\section{REVISTA DA ABRALIN}

(JB 25/2013) O jornal espanhol El País publicou reportagem NESTE DIA / $\mathbf{1}^{\mathbf{0}}$, intitulada "O polêmico 'jeitinho' brasileiro", na qual | analisa o comportamento da população e conclui que o | artifício, que de tempos pra cá tem sido denegrido, nada | mais é do que "arranjar uma saída para uma situação sem | saída".

Ao total, no período de 1980 a 2014, 04 exemplares apresentam o ponto de vista enunciado em primeira pessoa, marcando o plural inclusivo, e 08 textos apresentam o ponto de vista enunciativo em terceira pessoa, evidenciando vestígios de mudança, da primeira para a segunda geração, neste modo de dizer. Por outro lado, podemos afirmar que os dados apresentam traços de permanência no que diz respeito à expressão da cronografia por dêiticos temporais de natureza adverbial.

Dos 12 exemplares analisados na segunda geração, somente três não apresentam elementos dêiticos temporais de natureza adverbial, cabendo aos tempos verbais (expressos pelas desinências) o estabelecimento das coordenadas cronográficas nas cenografias variadas. Os trechos a seguir, de exemplares das décadas de 1980, 1990, 2000 e 2010 ilustram a ocorrência dos referidos elementos dêiticos temporais:

(JB 16/1988) Voltou o presidente Sarney da Argentina, onde I foi consolidar e projetar para o futuro as | iniciativas ATÉ AGORA tomadas no sentido da forma- I ção de um mercado comum regional.

(JB 17/1991) O papa João Paulo II inicia HOJE, por Natal, sua | segunda visita pastoral ao Brasil, com dez | dias de duração. Sua presença não poderia ser | mais oportuna, num momento em que o país | parece viver sua grande crise de fé.

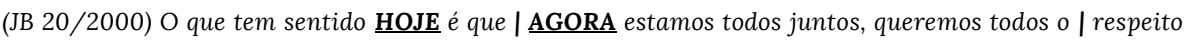
aos índios, a demarcação de suas ter- I ras, a defesa de sua cultura.

(JB 25/2014) O jornal espanhol El Pais publicou reportagem NESTE DIA |1 $\mathbf{1}^{\mathbf{0}}$, intitulada "O polêmico 'jeitinho' brasileiro", na qual | analisa o comportamento da população e conclui que o | artifício, que de tempos pra cá tem sido denegrido, nada | mais é do que "arranjar uma saída para uma situação sem | saída" e, portanto, tem ares de inteligência, além de uma| "criatividade ancestral".

Os dados da segunda geração também apresentam traços de permanência no que diz respeito à expressão da topografia por elementos dêiticos. Neste bloco de textos, assim como nos exemplares da primeira geração, a tendência é a marcação das coordenadas textuais por índices de natureza adverbial (dos 12 editoriais, 10 registram a ocorrência de advérbios e/ou locuções adverbiais de lugar; nos demais, depreende-se a topografia por informação cotextuais e/ou contextuais). Nos fragmentos expostos a seguir, é possível observar a ocorrência destes elementos dêiticos:

(JB 14/1982) Decorre, principalmente, do fato de | que do dia para a noite está criado um | precedente alarmante para a convivência | dos povos DESTE CONTINENTE.

(JB 19/1967) É irreparável o dano, NO PAÍS E NO EXTERIOR, | enquanto o episódio for lembrado - e por muito | tempo será lembrado - exatamente pela completa | inexistência de qualquer motivo para cinco ho- I mens, quatro dos quais recém-chegados à maiori- I dade, praticarem um ato gratuito ao preço de uma | vida humana.

(JB 21/2003) A esquerda chegou ao gover- | no NO BRASIL por via eleitoral. | Não gerou transtorno político | nem inquietação econômica | nem atritos sociais. 


\section{REVISTA DA ABRALIN}

(JB 24/2013) Na ocasião, o império perdia a força NO BRASIL tanto com a ala conservadora quanto com a | progressista.

Assim como na primeira geração, há poucas ocorrências de dêiticos sociais (editorial de 1985:

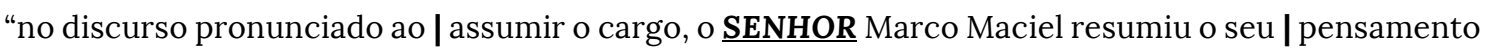
em uma frase digna de registro"), dêiticos modais (editorial de 2000: "ASSIM, do 4 de outubro de I 1582 passou-se não para o | dia 5, mas para o dia 15 de outubro") e dêiticos discursivo-textuais (editorial de 2006: "Defendem-se | AQUI não mudanças super- | ficiais, aprovadas sobre o ca- | lor das crises políticas").

\section{Os editoriais do Clarín (CL)}

Por sua vez, os textos do CL apresentam recorrência de dêiticos de primeira pessoa (pronomes e verbos, notadamente), evidenciando o plural inclusivo como ponto de vista enunciativo, assim como nos textos do JB. Esta tradicional forma de dizer configura-se também no periódico argentino como uma estratégia de captação dos coenunciadores, pelo enunciador, no plano da argumentação, como se observa em sua recorrência ao longo dos séculos XX e XXI.

Na primeira geração de textos do CL, no período de 1946 a 1979, 11 (onze) exemplares apresentam o ponto de vista enunciativo expresso pela primeira pessoa, isto é, pelo "nós" com valor inclusivo. Somente o exemplar de 1976 apresenta a terceira pessoa como ponto de vista enunciativo. Os exemplos abaixo, organizados por décadas, ilustram a ocorrência de dêiticos (pronomes e verbos) na primeira pessoa do plural:

(CL 01/1946) En lugar de una solución así, I genuinamente argentina, con varios e fecun- I dos antecedentes en NUESTRA historia, se pre- I firió un expediente crudamente partidario, I en reminiscencias de "frente popular".

(CL 05/1958) En la actualidad, las estadísticas | NOS ASIGNAN unas 120.000 hectáreas de sauces y ála| mos, una cifra no muy alta de eucaliptos y apenas | 7.000 hectáreas de pinos y araucárias.

(CL 06/1961) Ya | OBSERVAMOS oportunamente, las cir- | cunstancias excepcionales en que ella | tendrá lugar, pero a la vez el acendra- I miento del espíritu de la unidad conti- I nental con que los pueblos de esta par- I te del mundo se disponen a encarar | sus presentes y eventuales dificulta- I des.

(CL 10/1973) Resulta así impres- I cindible una nueva estructuración | del sistema, fundado sobre sólidas | bases que no lesionen las soberanías | nacionales y la perspectiva de que | NUESTROS países alcancen al desa- | rrollo independiente.

A análise dos índices linguístico-discursivos pelos quais as diversas cenografias do CL se instauram na cena de enunciação revelou recorrências também dos dêiticos temporais e espaciais no plano da cronografia e da topografia, respectivamente. 


\section{REVISTA DA ABRALIN}

Neste tocante, todos os 12 exemplares da primeira geração de textos do periódico argentino apresentam elementos dêiticos temporais de natureza adverbial que, ao lado dos tempos verbais expressos pelas desinências, marcam o presente, com recorrente referência ao passado, como tempo da tradição editorialística. Os exemplos que destacamos a seguir ilustram esta projeção temporal:

(CL 01/1946) HOY, ante el hecho | consumado, no cabe sino reconocer paladi- | namente la legitimidad del triunfo del [...] en consecuencia.

(CL 03/1953) Con expresivo fervor patriótico la República celebró | AYER el Día de la Bandera.

(CL 08/1967) Como lo señalamos DÍAS PASADOS, resulta | urgente una nueva definición argentina | en el campo de la política continental.

(CL 09/1970) Los pueblos latinoamericanos abrumados | por el subdesarrollo y sedientos de jus- | ticia y liberación enfrentan $\underline{\mathrm{HOY}}$ no solo la | resistencia de quienes medran con el estanca- | miento.

Do mesmo modo, 10 exemplares da primeira geração do CL apresentam elementos dêiticos de natureza adverbial no estabelecimento da topografia nas diversas cenografias analisadas. Em geral, parte-se do geral para o particular (do contexto latino-americano para o contexto argentino), ou o contrário, em alguns casos. Somente os textos de 1946 e 1979, o primeiro e o último desta geração, não apresentam dêiticos temporais de natureza adverbial, cabendo às informações do contexto e do contexto o estabelecimento das coordenadas espaciais. Abaixo, destacam-se exemplos das décadas de 40, 50, 60 e 70 do século XX, em que a topografia se expressa por meio de elementos do campo dêitico espacial:

(CL 02/1949) La comunidad argentina ha visto fielmente | reflejada su concepción de | la vida, de la existencia y del destino a que aspira con I plena conciencia, en el enjundioso discurso | pronunciado por el presidente de la Repú- | blica en la sesión de clausura del Primer | Congreso Nacional de Filosofía reunido EN | MENDOZA.

(CL 04/1955) Un tango ruso. Eso tocaban en | una "boite" de un puerto del | Mar Negro el día en que pararon en | ella algunos marinos argentinos, | según ha referido recientemente | el médico de una de nuestras na- | ves mercantes, que en un periódico | italiano que se publica EN BUENOS | AIRES.

(CL 07/1964) Rindamos tributo a aquellas ge- I neraciones arriesgadas, compuestas I por hombres temblados en el servi- | cio de armas - milicos y paisanos | improvisados en la acción de guerra | contra el desierto y el salvaje -, y | hombres y mujeres llegados de todas | partes del mundo sin más bagaje que | su ánimo de trabajar y afincarse con | su hogar EN NUESTRO SUELO.

(CL 11/1976) El año de 1975 pasará a la histo- | ria económica de la mayoría | de los países subdesarrollados co- | mo uno de los períodos más nefas- | tos. EN AMÉRICA LATINA, Brasil y Mé- | xico debieron desacelerar sus | ritmos de crecimiento, mientras | que otros, como la Argentina, Chile, | Perú y Colombia, vieron descender | sus productos por debajo del | nivel del año anterior.

Ainda com relação à primeira geração de textos do CL, destaque-se que as ocorrências de dêiticos modais, sociais e discursivo-textuais são mais recorrentes que no JB. Nesta geração de textos, registram-se: (i) 04 ocorrências do dêitico modal "así", com valor circunstancial, nos exemplares de 


\section{REVISTA DA ABRALIN}

1946, 1949, 1964 e 1970; (ii) 02 ocorrências de dêiticos discursivo-textuais, "aquí" e "desde esas columnas", com valor metalinguístico, nos exemplares de 1961 e 1979; e (iii) 01 ocorrência do dêitico social "señor", expressando respeito do enunciador pelo coenunciador, no exemplar de 1961.

Já com relação aos textos da segunda geração no CL, que compreende o período de 1980 a 2014, observam-se traços de permanência na expressão do ponto de vista enunciativo. No período mencionado, registram-se 11 ocorrências de editoriais em primeira pessoa, com ocorrência do plural inclusivo. Somente dois exemplares, exatamente dos anos de 2013 e 2014, apresentam-se em $3^{\text {a }}$ pessoa. Exemplos dos dois casos são expostos a seguir: os de 1985 e 1991, referentes às ocorrências de primeira pessoa do plural, e os de 2013 e 2014. referentes às ocorrências de terceira pessoa:

(CL 14/1985) Este retoque a la ideología | sirve para mostrar que ningún | país del mundo moderno, ni si| quiera la segunda superpotencia | a pesar de inmensa concen- | tración de poder y recursos que | abarca, puede desdeñar en NUES- | TROS días la modernización.

(CL 16/1991) La relativamente breve histo- | ria de cuanto ocurrió con el edi- | ficio de Esmeralda y Corrientes | revela a las claras que es pro- | ducto de un Estado y de una po- | blación sin recursos económicos | suficientes para intentar salvar | de la destrucción algo que, por | ser parte del patrimonio común, | NOS PERTENECE a todos $y$, por lo | tanto, no debería poder ser moti- | vo de compra o venta.

(CL 24/2013) En un país en el que en broma o en serio casi | todos piensan que todo puede pasar, ESTALLÓ LA | SORPRESA. UN SHOCK DE EMOCIÓN Y ENTUSIASMO | en la gente, QUE MEZCLÓ AL HASTA AYER CARDENAL | BERGOGLIO con Messi y Máxima y otro que | encadenó fastidio y desconcierto en el Gobierno.

(CL 25/2014) En los últimos 26 años HUBO TRES | GRAVES CRISIS CON LA LUZ. || En 1988 El Chocón dejó de funcionar por el bajo caudal del río Limay. | En febrero de 1999 se rompió la central Azopardo de Edesur y la actual | se atribuye a la extendida ola de calor. || La diferencia es que en los casos anteriores los presidentes | dieron la cara.

Os editoriais da segunda geração do CL sinalizam para traços de permanência na expressão da cronografia e da topografia, nas cenografias, por elementos dêiticos de natureza adverbial. Dos 13 (treze) exemplares analisados, somente 01 (ano de 2009), não apresenta expressões adverbiais temporais, sendo as coordenadas de tempo recuperadas pelas desinências verbais. Do mesmo, somente 02 exemplares (1994 e 2006) não apresentam expressões adverbiais espaciais, cabendo às desinências verbais a função de expressar as coordenadas topográficas. Os exemplos a seguir ilustram a ocorrência dos elementos dêiticos temporais e espaciais, respectivamente, em textos dos séculos XX e XXI:

(CL 13/1982) La foto que este diario publicó AYER en su | primera plana [...] tiene tal vez | más elocuencia que muchas de las palabras | que hasta ahora hayan podido escribirse.

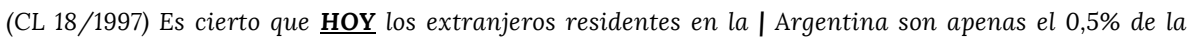
población.

(CL 23/2012) Cuesta encontrar en la historia argentina una | movilización popular como la de $\underline{\mathbf{A Y E R}}$. Además | de una multitud nunca vista, varias cosas más | la hacen única. 


\section{REVISTA DA ABRALIN}

(CL 15/1988) En las últimas décadas se re- | gistró EN LA MAYORÍA DE LOS | PAÍSES LATINOAMERICANOS un pro- | ceso de rápida urbanización que | devino en la creación de grandes | asentamientos con diferentes | grados de precariedad.

(CL 18/1997) El Día del Inmigrante, celebrado desde hace muchos años EN NUESTRO PAÍS | cada 4 de setiembre, evoca el surgimiento de una nación moderna que, | desde el vamos (sic), fue el resultado de una confluencia de procesos | migratorios de distintas procedencias y contextos históricos y culturales.

Por fim, se comparada ao primeiro bloco de textos, a segunda geração apresenta menos ocorrências de dêiticos modais (a expressão circunstancial "así" aparece em três editoriais, nos anos de 1988, 2006 e 2014) e nenhuma ocorrência de dêiticos sociais e discursivos-textuais. Assim como no $\mathrm{JB}$, a totalidade de ocorrências dos referidos elementos é bem menor se comparada à dos dêiticos de pessoa, de tempo e de espaço

\section{Considerações finais}

Para finalizar o debate dos dados expostos, destaco que, pela relação que estabelecem entre si em diferentes momentos da história dos textos, como indícios que se repetem no plano da diacronia, estes índices linguístico-discursivos sinalizam para a formação de tradições do dizer, como vemos no seguinte quadro-síntese:

\begin{tabular}{|c|c|c|}
\hline & 1a GERAÇÃO (1945 a 1979) & 2a GERAÇÃO (1980 a 2014) \\
\hline JB & $\begin{array}{l}\text { Dêixis pessoal: predomínio de dêiticos na } \\
\text { primeira pessoa, ou seja, no plural inclusivo } \\
\text { (expressão do ponto de vista enunciativo); } \\
\text { Dêixis temporal: predomínio de dêiticos } \\
\text { temporais de natureza adverbial (expressão } \\
\text { de tempo presente que se reporta a um } \\
\text { passado próximo e/ou a um passado } \\
\text { distante); } \\
\text { Dêixis espacial: predomínio de dêiticos } \\
\text { espaciais de natureza adverbial } \\
\text { (contextualização da enunciação no eixo } \\
\text { Brasil-América Latina); }\end{array}$ & $\begin{array}{l}\text { Dêixis pessoal: predomínio de dêiticos na terceira } \\
\text { pessoa (expressão do ponto de vista enunciativo), } \\
\text { evidenciando vestígios de mudança nesta } \\
\text { categoria; } \\
\text { Dêixis temporal: predomínio de dêiticos } \\
\text { temporais de natureza adverbial (expressão de } \\
\text { tempo presente que se reporta a um passado } \\
\text { próximo e/ou a um passado distante), } \\
\text { evidenciando traços de permanência; } \\
\text { Dêixis espacial: predomínio de dêiticos espaciais } \\
\text { de natureza adverbial (contextualização da } \\
\text { enunciação no eixo Brasil-América Latina), } \\
\text { evidenciando traços de permanência nesta } \\
\text { categoria; }\end{array}$ \\
\hline
\end{tabular}




\section{REVISTA DA ABRALIN}

\begin{tabular}{|c|c|c|}
\hline & $\begin{array}{l}\text { Dêixis social, modal e discursivo-textual: } \\
\text { poucas ocorrências }\end{array}$ & $\begin{array}{l}\text { Dêixis social, modal e discursivo-textual: poucas } \\
\text { ocorrências. }\end{array}$ \\
\hline \multirow[t]{4}{*}{ CL } & $\begin{array}{l}\text { Dêixis pessoal: predomínio de dêiticos na } \\
\text { primeira pessoa, ou seja, no plural inclusivo } \\
\text { (expressão do ponto de vista enunciativo); }\end{array}$ & $\begin{array}{l}\text { Dêixis pessoal: predomínio de dêiticos na primeira } \\
\text { pessoa, ou seja, no plural inclusivo (expressão do } \\
\text { ponto de vista enunciativo), evidenciando traços de } \\
\text { permanência nesta categoria; }\end{array}$ \\
\hline & $\begin{array}{l}\text { Dêixis temporal: predomínio de dêiticos } \\
\text { temporais de natureza adverbial (expressão de } \\
\text { tempo presente que se reporta a um passado } \\
\text { próximo e/ou a um passado distante); }\end{array}$ & $\begin{array}{l}\text { Dêixis temporal: predomínio de dêiticos temporais } \\
\text { de natureza adverbial (expressão de tempo presente } \\
\text { que se reporta a um passado próximo e/ou a um } \\
\text { passado distante), evidenciando traços de } \\
\text { permanência; }\end{array}$ \\
\hline & $\begin{array}{l}\text { Dêixis espacial: } \\
\text { espaciais de natureza }\end{array}$ & $\begin{array}{l}\text { Dêixis espacial: predomínio de dêiticos espaciais de } \\
\text { natureza adverbial (contextualização da enunciação } \\
\text { no eixo Argentina-América Latina), evidenciando } \\
\text { traços de permanência nesta categoria; }\end{array}$ \\
\hline & $\begin{array}{l}\text { Dêixis social, modal e discursivo-textual: } \\
\text { poucas ocorrências. }\end{array}$ & $\begin{array}{l}\text { Dêixis social, modal e discursivo-textual: poucas } \\
\text { ocorrências. }\end{array}$ \\
\hline
\end{tabular}

QUADRO 1 - Tradição e atualização do campo dêitico do JB e do CL Fonte: elaborado pelo autor.

A análise exposta em síntese no quadro acima disposto permite confirmar que o discurso é, de fato, "um espaço de regularidades enunciativas" (MAINGUENEAU, 2008, p. 15) observáveis em termos de sua expressão no plano diacrônico e que o diálogo estabelecido, nesta pesquisa, entre Filologia e Análise do Discurso se mostra promissor para empreendimentos investigativos em que história, língua e cultura se encontram em função da análise de objetos de estudo diacrônicos. Trata-se, a meu ver, de uma interface promissora para os estudos enunciativos contemporâneos que se interessam, cada vez mais, pela análise de fenômenos relacionados à história da língua, em perspectiva micro, e à história dos textos, dos gêneros e dos discursos, em perspectiva macro. 


\section{REVISTA DA ABRALIN}

\section{REFERÊNCIAS}

BENVENISTE, É. Problemas de Linguística Geral I. Campinas: Pontes, 1995.

CAVALCANTE, M. M. Expressões indiciais em contextos de uso: por uma caracterização dos dêiticos discursivos. 2000. 218 f. Tese (Doutorado em Linguística) - Programa de Pós-Graduação em Letras, Universidade Federal de Pernambuco, Recife, 2000

COSERIU, E. Lições de linguística geral. Rio de Janeiro: Imperial Novo Milênio, 1980.

FONSECA, F. I. Dêixis e pragmática linguística. In: FARIA, I. H.; PEDRO, E. R., I. DUARTE, I.; GOUVEIA. C. (Orgs). Introdução à Linguística Geral e Portuguesa. Lisboa: Caminho, 1996, 437-445

KABATEK, J. ¿Cómo investigar las tradiciones discursivas medievales? In: KABATEK, J.; JACOB, D. Lengua medieval y tradiciones discursivas en la Península Iberica: descripción gramatical, pragmática histórica, metodología. Madrid: Ibero-americana, 2001b, p. 97-132.

KABATEK, J. Prólogo. In: COSERIU, E. Lenguaje y discurso. Pamplona: EUNSA, 2006, p. 09-12.

KABATEK, J. Tradições discursivas e mudança linguística. Alemanha, set. 2007. Disponível em: <http://www.romling.uni-tuebingen.de/discurso/itaparica.pdf>. Acesso em: 26 out. 2013.

KABATEK, J.; JACOB, D. Lengua, texto y cambio lingüístico en la Edad Media iberorrománica. In: KABATEK, J.; JACOB, D. Lengua medieval y tradiciones discursivas en la Península Iberica: descripción gramatical, pragmática histórica, metodología. Madrid: Ibero-americana, 2001a, p. 07-18.

KOCH, P. Diskurstraditionen: zu ihrem sprachtheoretischen Status und ihrer Dynamik. In: FRANK, B.; HAYE, T.; TOPHINKE, D. Gattungen mittelalterlicher Schriftlichkeit. Tübingen: Narr, 1997, p. 43-79.

MAINGUENEAU. D. A propósito do ethos. In: MOTTA, A. R.; SALGADO, L. Ethos discursivo. São Paulo: Contexto, 2011, p. 11-29.

OESTERREICHER, W. La 'recontextualización' de los géneros medievales como tarea hermenéutica. In: KABATEK, J.; JACOB, D. Lengua medieval y tradiciones discursivas en la Península Iberica: descripción gramatical, pragmática histórica, metodología. Madrid: Ibero-americana, 2001, p. 199-231.

ZAVAM, A. S. Por uma abordagem diacrônica dos gêneros do discurso à luz da concepção de Tradição Discursiva: um estudo com editoriais de jornais. 2009. 420 f. Tese (Doutorado em Linguística) - Programa de Pós-Graduação em Linguística, Universidade Federal do Ceará, Fortaleza, 2009. 